\title{
Unravelling the expression of interleukin-9 in chronic rhinosinusitis: A possible role for Staphylococcus aureus
}

Tim Delemarre ${ }^{1}$, Natalie De Ruyck', Gabriele Holtappels ${ }^{1}$, Claus Bachert ${ }^{1,2,3^{*}+}$ and Elien Gevaert ${ }^{1 \dagger}$

\begin{abstract}
Chronic rhinosinusitis with nasal polyps (CRSwNP) is a Th2 biased inflammation, associated with nasal colonization of Staphylococcus (S.) aureus. Interleukin (IL)-9 is a pro-inflammatory Th2 cytokine with a pivotal role in asthma, allergy and chronic obstructive pulmonary disease (COPD), but is less studied in CRSWNP. We aimed to characterize the expression and cellular source of IL-9 and examined S. aureus as potential local trigger in CRSWNP. We showed increased numbers of interleukin-9 producing neutrophils and mononuclear cells in the tissue of CRSwNP patients. This interleukin-9 production was stimulated by $S$. aureus and its enterotoxin B in vitro. These findings underline the contribution of S. aureus and define IL-9 as another relevant cytokine in type 2 CRSwNP.
\end{abstract}

Keywords: Chronic rhinosinusitis with nasal polyps, Interleukin-9, Staphylococcus aureus

To the Editor

Chronic rhinosinusitis with nasal polyps (CRSwNP) is a chronic Th2 biased inflammation of the sinonasal mucosa, with patients suffering facial pressure, nasal obstruction and reduced smell caused by the presence of nasal polyps and excessive sticky mucus production [1]. CRSwNP is associated with nasal colonization of Staphylococcus $(S$.$) aureus in 67 \%$ of the patients [2]. $S$. aureus can infiltrate the nasal mucosa and modulate the CRSwNP pathogenesis via secretion of enterotoxins (Toxic shock syndrome toxin-1 (TSST-1), $S$. aureus enterotoxin A and B (SEA and SEB)), which causes an excessive stimulation of T-cells through their

\footnotetext{
*Correspondence: Claus.Bachert@ugent.be

${ }^{\dagger}$ Claus Bachert and Elien Gevaert shared project supervision

1 Department of Head \& Skin, Upper Airways Research Laboratory, Faculty of Medicine, Ghent University, C. Heymanslaan 10, 9000 Ghent, Belgium

Full list of author information is available at the end of the article
}

superantigen function. More specifically, S. aureus contributes to the polarization of type 2 immune responses in CRSwNP, characterized by increased levels of Th2 cytokines as interleukin (IL)-4, IL-5 and IL-13 [3]. IL-9 is another pro-inflammatory Th2 cytokine that plays a pivotal role in multiple chronic airway inflammations as asthma, chronic obstructive pulmonary disease (COPD) and allergy, but is less studied in CRSwNP [4]. In asthmatic animal models and in vitro experiments, IL-9 causes bronchial hyperresponsiveness, lung eosinophilia, elevated levels of IgE, increased mucin secretion and subepithelial accumulation of collagen - all major characteristics of the CRSwNP pathogenesis [5-7]. In addition, concentrations of IL-9 in bronchoalveolar lavage correlate with clinical parameters of bronchoconstriction in asthmatic patients [6]. Despite the clear effects of IL- 9 on other respiratory diseases, studies on IL-9 in CRSwNP are rather limited, and cellular sources, triggers of IL-9 production and possible functions in CRSwNP are still unidentified. Therefore, we aimed to characterize the expression of IL-9 and IL-9R, and made use of $S$. aureus as local trigger of IL-9 production in the tissue of CRSwNP patients. Details of methods and materials used 
in this study are shown in Additional file 1: Materials and methods. Patient characterization of the subjects used in this study is summarized in Additional file 2: Table S1.

Both $l L 9$ and IL9R gene expression were found significantly increased in CRSwNP $(\mathrm{n}=40)$ compared to control $(\mathrm{n}=20)$ tissues $(\mathrm{p}<0.05$ and $\mathrm{p}<0.001$; Fig. $1 \mathrm{a}, \mathrm{b})$. As IL-9 protein levels in the tissue were undetectable via ELISA tests, further confirmation of increased IL-9 in CRSwNP was provided by quantification of IL-9+ cells via immunohistochemistry (IHC) staining. Indeed, numbers of IL- $9^{+}$cells were found significantly increased in CRSwNP $(n=13)$ compared to controls $(n=5)(\mathrm{p}<0.01$; Fig. 1c). These findings are in line with an earlier study in Caucasian patients showing the increased presence of IL- $9^{+}$cells in CRSwNP, while to the best of our knowledge, this is the first report describing increased IL-9R expression in Caucasian CRSwNP [8]. In addition, we found significantly elevated numbers of IL- $9^{+}$cells in CRSwNP patients with comorbid asthma $(n=8)$, compared to those without comorbid asthma $(\mathrm{n}=5)(\mathrm{p}<0.05$; Additional file 3: Fig. S1). No association was observed between local IL-9 production and the patients' allergy status (data not shown). Related to these observations, it was shown that numbers of IL-9-expressing cells are increased in asthmatic airways compared to healthy controls and in bronchial biopsies of asthmatic patients with nasal polyps compared to those without nasal polyps [6].

Morphologic analysis of the IHC stainings further showed that, similar to asthmatic models, the main producers of IL-9 in CRSwNP were mononuclear
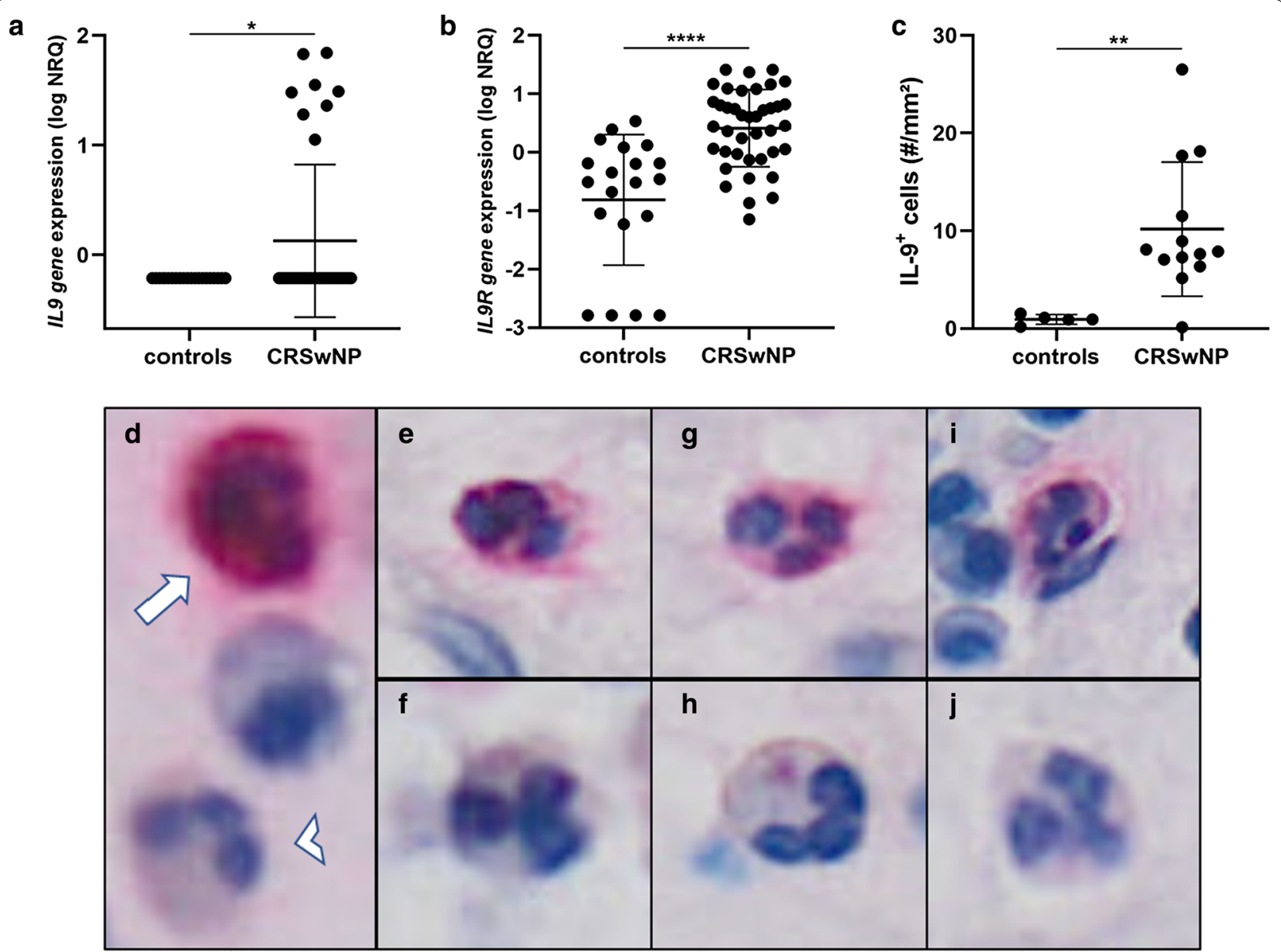

Fig. 1 IL9-IL9R gene expression and numbers of IL-9+ cells are increased in CRSWNP compared to controls. a /L9 and $\mathbf{b}$ /L9R gene expression were significantly (resp. $p<.05$ and $p<.0001)$ increased in tissue of CRSWNP $(n=40)$ compared to controls $(n=20)$. c Significantly $(p<.01)$ increased numbers of IL- $9^{+}$cells were observed in tissue of CRSWNP $(n=13)$ compared to controls $(n=5)$. Gene expression is expressed as normalized relative quantity (NRQ). $\mathbf{d ~ I L - 9 ^ { + }}$ neutrophil (arrow) and IL-9- neutrophil (arrowhead) located near each other in the same patient. Both IL-9 $9^{+}$neutrophils (e, $\mathbf{g}, \mathbf{i})$ and IL-9- neutrophils $(\mathbf{f}, \mathbf{h}, \mathbf{j})$ were observed in patients with CRSWNP. Levels of statistical significance are expressed as ${ }^{*} \mathrm{p}<.05,{ }^{* *} \mathrm{p}<.01,{ }^{* * *} \mathrm{p}<.001$ and ${ }^{* * *} p<.0001$ 
cells and neutrophils [4]. Interestingly, only a fraction $(80.1 \pm 14.0 \%)$ of the neutrophils were IL-9 positive (Fig. $1 \mathrm{~d}-\mathrm{j}$ ), which might indicate that IL-9 production in neutrophils is subtype, micro-environment or activation dependent. Besides classic triggering of the $\mathrm{T}$-cell receptor, $\mathrm{CD} 4(+)$ T-cells require an additional stimulus to produce and secrete IL-9 [7]. CRSwNP pathology is affected by $S$. aureus and its enterotoxins as described above, but the effect of $S$. aureus and SEB on IL-9 production is still unknown. We therefore stimulated peripheral blood derived mononuclear cells (PBMCs) with vehicle (NS), lipopolysaccharide (LPS), S. epidermidis, S. aureus and SEB for $24 \mathrm{~h}$ and analyzed the IL9 gene expression in 7 independent experiments. Significant increases in $I L 9$ gene expression were observed in PBMCs upon stimulation with $S$. aureus $(\mathrm{p}<0.001)$ and SEB $(\mathrm{p}<0.01)$, but not with S. epidermidis and LPS (Fig. 2). Moreover, the increase in IL9 gene expression in PBMCs was concentration dependent for S. aureus (Additional file 4: Fig. S2). Interestingly, $S$. aureus is a very specific trigger for IL-9 production as no increase was observed upon stimulation with the same concentration of S. epidermidis. These observations are in line with earlier findings from our group showing that $S$. aureus colonization is associated with type 2 immune responses and that SEB can induce the production of several type 2 cytokines as IL-4, IL-5 and IL-13 in CRSwNP [2,9]. To confirm our findings, CRSwNP tissue cubes were stimulated with $S$. aureus and SEB, but due to low RNA quality after stimulation, and the absence of a SEB-compatible ELISA kit, we were

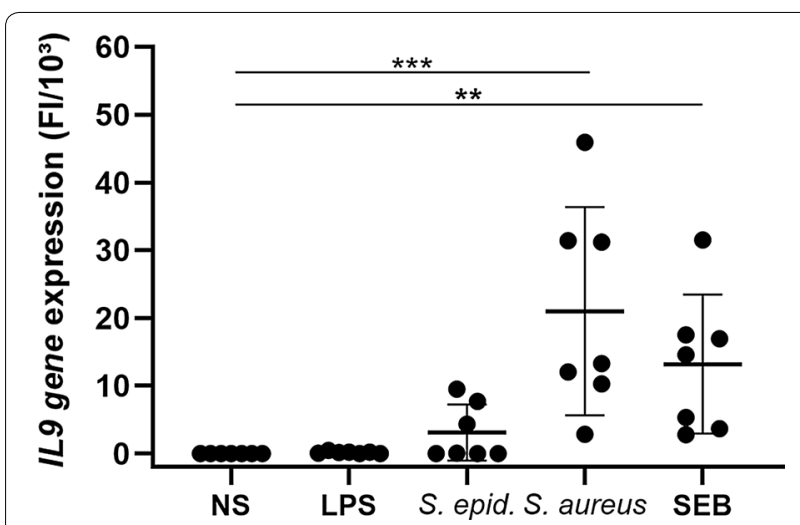

Fig. 2 S. aureus induced IL9 gene expression in PBMCs. Levels of IL9 gene expression in PBMCs after $24 \mathrm{~h}$ stimulation with culture medium (NS), LPS $(1 \mu \mathrm{g} / \mathrm{ml})$, S. epidermidis ( $\left.10^{5} \mathrm{CFUs} / \mathrm{ml}\right)$, S. aureus ( $10^{5} \mathrm{CFUs} /$ $\mathrm{ml})$ and SEB $(1 \mu \mathrm{g} / \mathrm{ml})$ in $\mathrm{n}=7$ independent experiments. IL9 gene expression in significantly increased upon $24 \mathrm{~h}$ stimulation with $\mathrm{S}$. aureus $(p<.001)$ and SEB $(p<.01)$, but not upon stimulation with S. epidermidis and LPS. Levels of gene expression are expressed as fold induction (FI) versus non stimulated conditions, divided by $10^{3}$. Levels of statistical significance are expressed as ${ }^{*} \mathrm{p}<.05,{ }^{* *} \mathrm{p}<.01$, ${ }^{* * *} p<.001$ and $^{* * * *} p<.0001$ unable to measure IL-9 production ex vivo. Altogether, we showed here that the increased levels of IL-9 in CRSwNP are produced by a fraction of neutrophils and mononuclear cells and that the IL-9 production in mononuclear cells is stimulated by $S$. aureus and its enterotoxin B. The increased levels of IL-9 in CRSwNP could play a vital role in the chronicity and severity of CRSwNP, but further research will be necessary to show the exact relevance of IL-9 in CRSwNP. These findings underline the contribution of $S$. aureus to the CRSwNP pathogenesis, and define IL- 9 as another relevant cytokine, upregulated with type 2 cytokines such as IL-4, IL-5, IL-13 and others, which deserves further study.

\section{Supplementary information}

Supplementary information accompanies this paper at https://doi. org/10.1186/s13601-020-00348-5.

Additional file 1. Materials and methods.

Additional file 2: Table S1. Patient characterization.

Additional file 3: Figure S1. Numbers of nasal tissue IL-9+ cells associated with comorbid vs. no asthma. Numbers of IL-9+ cells are significantly increased in CRSwNP patients with comorbid asthma $(n=8)$, compared to those without asthma $(n=5)$. Patients were considered asthmatic based on their clinical records or diagnosis by a pneumologist. Levels of statistical significance are expressed as ${ }^{*} p<0.05,{ }^{* *} p<0.01,{ }^{* * *} p<0.001$ and ${ }^{* * *} p<0.0001$.

Additional file 4: Figure S2. Concentration dependency of IL9 gene expression of PBMCs on S. aureus. Significantly $(p<0.05)$ increased IL9 gene expression when PBMCs were stimulated with 100-fold numbers of S. aureus $(n=7)$. Levels of statistical significance are expressed as ${ }^{*} p<0.05$, ${ }^{* *} p<0.01,{ }^{* * *} p<0.001$ and ${ }^{* * *} p<0.0001$.

Abbreviations

CRSwNP: Chronic rhinosinusitis with nasal polyps; S. aureus: Staphylococcus aureus; S. epidermidis: Staphylococcus epidermidis; TSST-1: Toxic shock syndrome toxin 1; SEA: Staphylococcus aureus enterotoxin A; LPS: Lipopolysaccharide; SEB: Staphylococcus aureus enterotoxin B; IL: Interleukin; COPD: Chronic obstructive pulmonary disease; IgE: Immunoglobulin E; PBMCs: Peripheral blood mononuclear cells.

\section{Acknowledgements}

Not applicable.

\section{Authors' contributions}

TD contributed to conception and design of the work, acquisition, analysis and interpreting of data and drafting of the work; NDR and GH contributed to acquisition and analysis of data and substantively revising the work; CB and EG shared project supervision and contributed to conception and design of the work, interpreting of the data and substantively revised the work. All authors read and approved the final manuscript.

\section{Funding}

E.G. was supported by a post-doctoral research fellowship from the FWO (FWO/DPO/108). C.B. and E.G. were supported by grants from FWO Flanders (1515516N, EOS project nr. GOG2318N) and the Interuniversity Attraction Poles Grant P7/30.

Availability of data and materials All data generated or analyzed during this study are included in this published article and its additional files. 
Ethics approval and consent to participate

The study was approved by the local Ethics Committee of Ghent University Hospital (B670201939934). Written informed consent was received from all patients before inclusion in the study.

\section{Consent for publication}

Not applicable.

\section{Competing interests}

The authors declare that they have no competing interests.

\section{Author details}

${ }^{1}$ Department of Head \& Skin, Upper Airways Research Laboratory, Faculty of Medicine, Ghent University, C. Heymanslaan 10, 9000 Ghent, Belgium.

${ }^{2}$ Division of ENT Diseases, CLINTEC, Karolinska Institute, Stockholm, Sweden.

${ }^{3}$ International Airway Research Center, First Affiliated Hospital, Sun Yat-Sen

University, Guangzhou, China.

Received: 4 June 2020 Accepted: 30 September 2020

Published online: 29 October 2020

\section{References}

1. Schleimer RP. Immunopathogenesis of chronic rhinosinusitis and nasal polyposis. Annu Rev Pathol. 2017;12:331-57.

2. Van Zele T, Gevaert P, Watelet JB, Claeys G, Holtappels G, Claeys C, et al. Staphylococcus aureus colonization and IgE antibody formation to enterotoxins is increased in nasal polyposis. J Allergy Clin Immunol. 2004; 114(4):981-3.

3. Teufelberger AR, Broker BM, Krysko DV, Bachert C, Krysko O. Staphylococcus aureus orchestrates type 2 airway diseases. Trends in molecular medicine. 2019;25(8):696-707.

4. Chakraborty S, Kubatzky KF, Mitra DK. An update on interleukin-9: from its cellular source and signal transduction to is role in immunopathogenesis. Int J Mol Sci. 2019;20(9):2113.

5. Temann UA, Geba GP, Rankin JA, Flavell RA. Expression of interleukin 9 in the lungs of transgenic mice causes airway inflammation, mast cell hyperplasia, and bronchial hyperresponsiveness. J Exp Med. 1998;188(7):1307-20.

6. Neurath MF, Finotto S. IL-9 signaling as key driver of chronic inflammation in mucosal immunity. Cytokine Growth Factor Rev. 2016;29:93-9.

7. Kaplan MH, Hufford MM, Olson MR. The development and in vivo function of T helper 9 cells. Nat Rev Immunol. 2015;15(5):295-307.

8. Olcott CM, Han JK, Cunningham TD, Franzese CB. Interleukin-9 and interleukin-17C in chronic rhinosinusitis. Int Forum Allergy Rhinol. 2016;6(8):841-7.

9. Patou J, Van Zele T, Holtappels G, Gevaert P, Van Cauwenberge P, Bachert C. Staphylococcus aureus enterotoxin B stimulation in nasal polyps. J Allergy Clin Immunol. 2007;119(1):S243.

\section{Publisher's Note}

Springer Nature remains neutral with regard to jurisdictional claims in published maps and institutional affiliations.
Ready to submit your research? Choose BMC and benefit from:

- fast, convenient online submission

- thorough peer review by experienced researchers in your field

- rapid publication on acceptance

- support for research data, including large and complex data types

- gold Open Access which fosters wider collaboration and increased citations

- maximum visibility for your research: over $100 \mathrm{M}$ website views per year

At BMC, research is always in progress.

Learn more biomedcentral.com/submissions 